Annals of International Medical and Dental Research

E-ISSN: 2395-2822 | P-ISSN: 2395-2814

Vol-8, Issue-1 | January-February 2022

DOI: $10.53339 /$ aimdr.2022.8.1.31

Page no- 235-242 | Section- Research Article (Surgery)

\title{
Complications after Stapled Hemorrhoidectomy: A Single Center Experience
}

\section{Md. Abdul Jali1 ${ }^{*}$, Md. Omar Faruk², M. Mohibul Aziz ${ }^{3}$}

\author{
${ }^{1}$ Assistant Professor, Department of Surgery, \\ Ibn Sina Medical College and Hospital, Dhaka, \\ Bangladesh. \\ Email: Jalilfcps17@gmail.com \\ Orcid ID: 0000-0001-5018-7887 \\ ${ }^{2}$ Assistant Professor, Department of Surgery, \\ Ibn Sina Medical College and Hospital, Dhaka, \\ Bangladesh. \\ Email: dr.omar1976@gmail.com \\ Orcid ID: 0000-0002-3932-1675 \\ 3Principal, Professor and Head, Department of \\ Surgery, Ibn Sina Medical College and \\ Hospital, Dhaka, Bangladesh. \\ Email: mohibul.aziz@hotmail.com \\ Orcid ID: 0000-0001-7470-8325 \\ *Corresponding author
}

Received: 06 October 2021

Revised: 14 November 2021

Accepted: 25 November 2021

Published: 22 December 2021

\begin{abstract}
Background: A circumferential strip of mucosa about 1.5 to 2 centimetres above the dentate line is removed in stapled hemorrhoidectomy, a new technique for haemorrhoids treatments. Objective: The aim of the study was to evaluate complications after stapled hemorrhoidectomy. Methods: A total of 101 patients between the age group 20 to 70 years were diagnosed with grade 3 and grade 4 haemorrhoids. Patients are included in stapled haemorrhoidectomy. The questionnaire focused on stapled hemorrhoidectomy procedures performed in the period July 2018 to June 2020. Descriptive analysis was done based on the student's T-test using SPSS 24 software version. The level of significance was set at $5 \%(p<0.05)$. Results: In the 2-years timeframe, out of 101 patients in the Immediate (within 1 week) complications of stapled hemorrhoidectomy, $84.16 \%$ were in None, $5.94 \%$ were severe pain, $3.96 \%$ were bleeding, $1.98 \%$ were Thrombosis, $0.99 \%$ were urinary retention, $1.98 \%$ were Anastomotic dehiscence $0.99 \%$ were Fissure, $0.99 \%$ were perineal intramural hematoma and $0.99 \%$ were submucosal abscess. Out of $90.09 \%$ were in none, $1.98 \%$ were Recurrent hemorrhoids, 0.99\% were Severe pain, Stenosis, Fissure, Skin tag, Thrombosis, Staples problems, Intramural abscess and Intussusception. Conclusion: Although stapled hemorrhoidectomy appears to be promising, we believe that a multicenter randomized controlled trial with a long-term follow-up comparing stapled hemorrhoidectomy and banding is required before the treatment can be recommended. The majority of difficulties can be avoided by following the rectal wall anatomy during the surgery.
\end{abstract}

Keywords:- Stapled hemorrhoidectomy, Complications, hemorrhoids.

\section{INTRODUCTION}

Conventional open and closed hemorrhoidectomies deal with internal and external haemorrhoids and associated anal pathology. Stapled hemorrhoidectomy, a new approach to the treatment of haemorrhoids, removes a circumferential strip of mucosa about 1.5 to 2 centimetres above the dentate line with a circular stapler, probably interrupting the hemorrhoidal vessels and stretching the prolapsed mucosa. Major complications of conventional hemorrhoidectomy are early or late haemorrhage, anal stenosis and fissures. In 
Annals of International Medical and Dental Research

E-ISSN: 2395-2822 | P-ISSN: 2395-2814

Vol-8, Issue-1 | January-February 2022

DOI: 10.53339/aimdr.2022.8.1.31

Page no- 235-242 | Section- Research Article (Surgery)

addition, other complications or complaints after hemorrhoidectomy have been reported such as pain, urinary retention, urinary tract infection, mucosal prolapse, pseudopolyps, epidermal cyst, anal canal fistula, pruritis ani, faecal incontinence and recurrent haemorrhoids.[1]

Complications reported for stapled hemorrhoidectomy are similar to those of open hemorrhoidectomy. In addition, other complications such as hemorrhoidal thrombosis, rectal anastomotic leakages with pelvic sepsis, rectal obstruction, retrorectal hematomas and Fournier gangrene have been reported. $[2,3,4,5,6]$ In 2001, during a 2-week period, 8 patients were observed for late complications of stapled hemorrhoidectomy performed 2-24 months previously (B. Ravo, unpublished observations). The patients complained of fissure $(n=7)$, pain $(n=5)$, hypertrophied anal papilla $(n=3)$, proctalgia Fugax $(n=1)$, and thrombosis $(n=1)$. The patients had a mean age of 51 years (range, 3065 years). A review of the literature revealed that articles on the complications of stapled hemorrhoidectomy reported less than 100 cases each and that the outcome of the procedure was mixed. $[7,8,9,10,11,12,13,14,15,16,17,18]$ An ad hoc questionnaire (B. Ravo) was sent to various Italian centres where stapled hemorrhoidectomy was being carried out, to determine major, minor and new complications of the procedure in a larger sample of patients and to evaluate if these complications could have been prevented.

The risks associated with stapled hemorrhoidectomy are similar to those associated with open hemorrhoidectomy. Other complications have been recorded, including hemorrhoidal thrombosis, rectal anastomotic leaks with pelvic sepsis, rectal blockage, retrorectal hematomas, and Fournier gangrene. $[1,2,3,4,5]$ Internal and external haemorrhoids, as well as accompanying anal disease, are treated with traditional open and closed hemorrhoidectomies. Stapled hemorrhoidectomy is a new method of treating haemorrhoids.

Because haemorrhoids are expected to become asymptomatic, they are not treated. Early or late haemorrhage, anal stenosis, and fissures are the most common consequences after traditional hemorrhoidectomy. Pain, urinary retention, urinary tract infection, mucosal prolapse, pseudopolyps, epidermal cyst, anal canal fistula, pruritis ani, faecal incontinence, and recurring haemorrhoids have all been recorded as problems or complaints following hemorrhoidectomy.[6] Eight patients were examined for late sequelae of stapled hemorrhoidectomy performed 2-24 months prior during a 2-week period in 2001. (B. Ravo, unpublished observations). Fissure $(n=7)$, discomfort $(\mathrm{n}=5)$, hypertrophied anal papilla $(n=3)$, proctalgia Fuga $(n=1)$, and thrombosis $(n=1)$ were all reported by the patients. The patients were 51 years old on average (range 30-65 years). According to a review of the literature, studies on the consequences of stapled hemorrhoidectomy each reported less than 100 cases, with variable results. $[7,8,9,10,11,12,13,14,15,16,17,18]$

\section{MATERIAL AND METHODS}

A prospective comparative Hospital-based study was conducted at Ibn Sina Medical College \& Hospital, Dhaka. A sample size of 101 subjects was estimated by assuming the 
Annals of International Medical and Dental Research

E-ISSN: 2395-2822 | P-ISSN: 2395-2814

Vol-8, Issue-1 | January-February 2022

DOI: $10.53339 /$ aimdr.2022.8.1.31

Page no- 235-242 | Section- Research Article (Surgery)

mean operating time as about 30 minutes in the staple group. A statistical power of $90 \%$ and 2sided alpha errors of $5 \%$ was considered for sample size calculation. To account for a loss to follow up of about 5\% another 2 subjects were added. A total of 101 patients aged 20 to 70 years diagnosed with grade III and grade IV haemorrhoids were recruited in the study consecutively by convenient sampling till the sample size is reached. Signed informed consent was obtained for all subjects, the confidentiality of the study participants was maintained. The data collection for the study was done from July 2018 to June 2020 for a period of 2 years including follow-up. Stapler hemorrhoidectomy (101 patients). The participants were evaluated by thorough clinical history, clinical examination and proctoscopy.

Technique: Surgery was performed under spinal anaesthesia, with the patient in the lithotomy position. Stapled hemorrhoidectomy was performed after preparing the anal canal (operating surface), and Proctoscopy examination. Stapler was closed with continued traction to the sutures until the maximum was reached. The stapler was deployed and held in place for 2 minutes. The doughnut was verified. The staple line was checked for its position above the dentate line, and hemostasis for bleeding sites. During the surgery, intraoperative time and intraoperative bleeding were assessed and recorded. All complications and their response to treatment were recorded during the period. The cost was assessed by the duration of hospital stay, time to resume normal activities in both the groups and all the patients were followed up for 6 months after the surgery to assess the development of recurrence and long-term complications like anal stenosis and anal incontinence.

\section{RESULTS}

In the 2-years timeframe, out of 101 patients in the Immediate (within 1 week) complications of stapled hemorrhoidectomy, $84.16 \%$ were in None, $5.94 \%$ were severe pain, $3.96 \%$ were bleeding, $1.98 \%$ were Thrombosis, $0.99 \%$ were urinary retention, $1.98 \%$ were Anastomotic dehiscence $0.99 \%$ were Fissure, $0.99 \%$ were perineal intramural hematoma and $0.99 \%$ were submucosal abscess. Out of $90.09 \%$ were in none, $1.98 \%$ were Recurrent hemorrhoids, 0.99\% were Severe pain, Stenosis, Fissure, Skin tag, Thrombosis, Staples problems, Intramural abscess and Intussusception.

Table 1: Late complications of stapled hemorrhoidectomy reported $(n=101)$ patients treated in a 1year period

\begin{tabular}{|l|l|l|}
\hline Complication & $\mathbf{n = 1 0 1}$ & \% \\
\hline None & 91 & 90.09 \\
\hline Recurrent hemorrhoids & 2 & 1.98 \\
\hline Severe pain & 1 & 0.99 \\
\hline Stenosis & 1 & 0.99 \\
\hline Fissure & 1 & 0.99 \\
\hline Bleeding & 0 & 0.0 \\
\hline
\end{tabular}


Annals of International Medical and Dental Research

E-ISSN: 2395-2822 | P-ISSN: 2395-2814

Vol-8, Issue-1 | January-February 2022

DOI: $10.53339 /$ aimdr.2022.8.1.31

Page no- 235-242 | Section- Research Article (Surgery)

\begin{tabular}{|l|l|l|}
\hline Skin tag & 1 & 0.99 \\
\hline Thrombosis & 1 & 0.99 \\
\hline Papillary hypertrophy & 0 & 0.0 \\
\hline Fecal urgency & 0 & 0.0 \\
\hline Staples problems & 1 & 0.99 \\
\hline Flatus incontinence & 0 & 0.0 \\
\hline Partial dehiscence & 0 & 0.0 \\
\hline Intramural abscess & 1 & 0.99 \\
\hline Intussusception & 1 & 0.99 \\
\hline Total & 101 & 100.0 \\
\hline
\end{tabular}

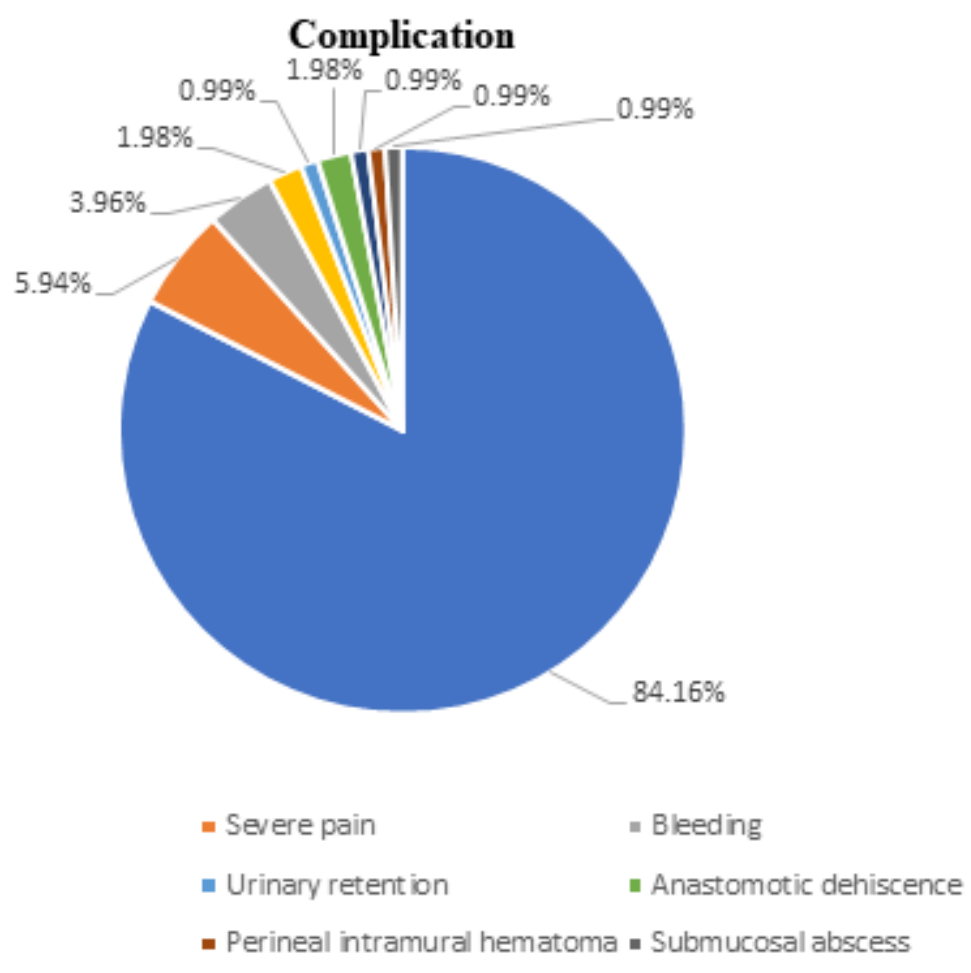

Figure 1: Immediate (within 1 week) complications of stapled hemorrhoidectomy (n=101)

\section{DISCUSSION}

The rectal mucosa is thrown into a longitudinal folder, known as columns of Morgagni when the anal canal enters the pelvis floor. The inner haemorrhoid plexus, made from sinusoids, is present in the underlying mucosa. $[9,10]$ Anal mucous membranes can spread through haemorrhoid sinusidation and conjunctive tissue coil formation when the sphincters relax and fold when the sphincter contracts and form a spongy coating that closes the anal channel. The unknown is the flow of blood and the vassal congestion of these sinusoids. 
Annals of International Medical and Dental Research

E-ISSN: 2395-2822 | P-ISSN: 2395-2814

Vol-8, Issue-1 | January-February 2022

DOI: 10.53339/aimdr.2022.8.1.31

Page no- 235-242 | Section- Research Article (Surgery)

Common sense suggests that an expansion of these sinusoids can contribute to continuity in times of urgency, such as stress, weight lifting and constipation due to the increase in pelvic pressure. This may explain why haemorrhoid encompassment is usually not constant and, when needed, can become physiological. A new approach to treating haemorrhoids is the circular stapled hemorrhoidectomy technique. A circular stapler is used to remove a circumferential strip of rectal mucosa about four centimetres above the dentate line, stretching the prolapsed mucosa if it is not fixed. This most likely disrupts the hemorrhoidal vessels. Contrary to what Longo suggested, removing a circumferential strip of mucosa in the rectum at or above the pelvic floor does not necessarily mean that the anal mucosa is stretched up from the anal canal, because the more redundant circumferential rectal mucosa may be pulled down into the anal canal, leaving the longitudinal anal fold intact. [7] Going to stretch the anal mucosa is also difficult if there is anal fibrosis, as with fissure. Complication rates after stapled hemorrhoidectomy range from $6.4 \%$ to $31 \% .10,11,12,13,14]$ Complications have been attributed by some authors to the surgeon's learning curve. This was not discovered in our research. The majority of complications occurred after the surgeon had completed more than 25 cases. In the first 25 cases performed, bleeding (48\%) was the most common immediate complication, as opposed to severe pain, which was the most common immediate complication overall. Given that the sympathetic and parasympathetic nerves innervate the rectal wall, excising the rectal mucosa should be painless. Pain is a common immediate complication of stapled hemorrhoidectomy, which is unusual. There may be a pain if the purse string for a stapler sits near the pelvic floor and involves muscle: $66 \%$ of the patients muscle in the doughnut have suffered from pain in this study. Even without muscles in the doughnut, some individuals may have pain since the muscle might instead have been inserted into the stapled lines. Bleeding is probably the second most frequently reported immediately due to the failure of haemostasis or to the excessive folded mucosa of the plywood line. Taking larger bites of the mucosa into the purse-string expands the space against which the staples are fired, making the staples ineffective for hemostasis. Avoiding placing the purse-string at the anal canal's inlet may aid in preventing the pelvic floor muscle from becoming entangled in the purse string's deep bites. Another complication of stapled hemorrhoidectomy was thrombosis, which was most likely caused by the fact that the haemorrhoid sinusoids were not removed and thus were easily traumatized during the procedure. Fissures may have formed as a result of too much-folded mucosa being included in the staple line. The larger mucosal fold can break and form a fissure, which will not heal until the staples are completely removed and the fissure is spread out. When a patient complains of hemorrhoidal symptoms again after stapled hemorrhoidectomy, the symptoms should not be classified as recurrent. This is due to the fact that the haemorrhoids are never actually removed. What is consistent is that the patient continues to complain about the issue that brought him to the doctor in the first place. In this study, rubber band ligation or Milligan-Morgan 
Annals of International Medical and Dental Research

E-ISSN: 2395-2822 | P-ISSN: 2395-2814

Vol-8, Issue-1 | January-February 2022

DOI: $10.53339 /$ aimdr.2022.8.1.31

Page no- 235-242 | Section- Research Article (Surgery)

hemorrhoidectomy was used to treat $72 \%$ of the patients who had recurrent symptoms.

Randomized clinical trials comparing stapled hemorrhoidectomies to Milligan-Morgan hemorrhoidectomies or other open and closed techniques have shown that the stapled procedure has less postoperative pain and a faster return to normal activities, but it is more expensive than conventional techniques and has a similar complication rate. $[7,8,9,10,11,12,13,14,15,16,17,18,19,20,21]$ Because they examine two alternative methods to the hemorrhoidal problem, these randomized trials between stapled hemorrhoidectomy and traditional surgical hemorrhoidectomy are not acceptable. External haemorrhoids and accompanying anal canal difficulties are not addressed by stapled hemorrhoidectomy, which leaves the pathology alone. Internal and external haemorrhoids, as well as accompanying disease, are treated by surgical hemorrhoidectomy. Banding, a therapeutical approach similar to stapled hemorrhoidectomy in which the redundant haemorrhoid folds are strangulated by a ring; the external haemorrhoids and associated pathologies are not treated, is, in our opinion, a therapeutical approach similar to stapled hemorrhoidectomy in which the redundant haemorrhoid folds are strangulated by a ring; the external haemorrhage. There hasn't been a published randomized controlled experiment comparing these two similar procedures. After a stapled hemorrhoidectomy, major complications such as pelvic infection, haemorrhage, blockage, and Fournier gangrene have been documented. $[3,4,5,6]$ Most technical problems can be avoided if the deeper layers of the rectal wall are respected and not included in the purse string, making a mucosal anastomosis that is needed for the stapled procedure, instead of an all-wall rectal layer anastomosis.

\section{Limitations of the Study}

This was an observational study with a small sized sample. So, the findings of this study may not reflect the exact scenario of the whole country.

\section{CONCLUSIONS}

In conclusion, these near fatal complications should be further evidence that this new technique should be approached and evaluated with caution. We propose that a multicenter, prospective randomized trial between stapled hemorrhoidectomy and banding (with a longterm follow-up) be performed before such a procedure is recommended, even though some early reports are promising.

\section{Recommendation}

This study can serve as a pilot to much larger research involving multiple centers that can provide a nationwide picture, validate regression models proposed in this study for future use and emphasize points to ensure better management and adherence.

\section{Acknowledgements}

The wide range of disciplines involved in complications after Stapled Hemorrhoidectomy research means that an Editors needs much assistance from referees in the evaluation of papers submitted for publication. I am very grateful to many colleagues for their thorough, helpful and 
Annals of International Medical and Dental Research

E-ISSN: 2395-2822 | P-ISSN: 2395-2814

Vol-8, Issue-1 | January-February 2022

DOI: $10.53339 /$ aimdr.2022.8.1.31

Page no- 235-242 | Section- Research Article (Surgery)

usually prompt response to requests for their opinion and advice.

\section{REFERENCES}

1. Shah KK, Pritt BS, Alexander MP. Histopathologic review of granulomatous inflammation. J Clin Tuberc Other Mycobact Dis. 2017;7:1-12. doi:10.1016/j.jctube.2017.02.001

2. Herold A, Kirsch JJ. Pain after stapled haemorrhoidectomy. Lancet. 2000;356(9248):2187. doi: 10.1016/s0140-6736(05)67258-3.

3. Molloy RG, Kingsmore D. Life threatening pelvic sepsis after stapled haemorrhoidectomy. Lancet. 2000;355(9206):810. doi: 10.1016/S0140-6736(00)02208$\mathrm{X}$.

4. Ravo B, Amato A, Bianco V, Boccasanta P, Bottini C, Carriero A, et al. Complications after stapled hemorrhoidectomy: can they be prevented? Tech Coloproctol. 2002;6(2):83-8. doi: 10.1007/s101510200018.

5. Ripetti V, Caricato M, Arullani A. Rectal perforation, retropneumoperitoneum, and pneumomediastinum after stapling procedure for prolapsed hemorrhoids: report of a case and subsequent considerations. Dis Colon Rectum. 2002;45(2):268-70. doi: 10.1007/s10350-004-6159-3.

6. MacRae HM, McLeod RS. Handsewn vs. stapled anastomoses in colon and rectal surgery: a metaanalysis. Dis Colon Rectum. 1998;41(2):180-9. doi: 10.1007/BF02238246.

7. Suankwan U, Larbcharoensub N, Viseshsindh $\mathrm{W}$, Wiratkapun C, Chalermsanyakorn P. A clinicopathologic study of tuberculous epididymoorchitis in Thailand. Southeast Asian J Trop Med Public Health. 2012;43(4):951-8.

8. Memish ZA, Venkatesh S. Brucellar epididymoorchitis in Saudi Arabia: a retrospective study of 26 cases and review of the literature. BJU Int. 2001;88(1):72-6. doi: 10.1046/j.1464-410x.2001.02243.x.

9. Siddharth P, Ravo B. Colorectal neurovasculature and anal sphincter. Surg Clin North Am. 1988;68(6):1185-200. doi: 10.1016/s00396109(16)44680-3.

10. Ganio E, Altomare DF, Gabrielli F, Milito G, Canuti S. Prospective randomized multicentre trial comparing stapled with open haemorrhoidectomy. Br J Surg.
2001;88(5):669-74.

doi:

10.1046/j.00071323.2001.01772.x.

11. Boccasanta P, Capretti PG, Venturi M, Cioffi U, De Simone M, Salamina G, et al. Randomised controlled trial between stapled circumferential mucosectomy and conventional circular hemorrhoidectomy in advanced hemorrhoids with external mucosal prolapse. Am J Surg. 200;182(1):64-8. doi: 10.1016/s0002-9610(01)00654-7.

12. Gabrielli F, Chiarelli M, Cioffi U, Guttadauro A, De Simone M, Di Mauro P, et al. Day surgery for mucosal-hemorrhoidal prolapse using a circular stapler and modified regional anesthesia. Dis Colon Rectum. 2001;44(6):842-4. doi: 10.1007/BF02234705.

13. Shalaby R, Desoky A. Randomized clinical trial of stapled versus Milligan-Morgan haemorrhoidectomy. Br J Surg. 2001;88(8):1049-53. doi: 10.1046/j.00071323.2001.01830.x.

14.Pernice LM, Bartalucci B, Bencini L, Borri A, Catarzi $S$, Kröning K. Early and late (ten years) experience with circular stapler hemorrhoidectomy. Dis Colon Rectum. 2001;44(6):836-41. doi: 10.1007/BF02234704.

15. Memish ZA, Venkatesh S. Brucellar epididymoorchitis in Saudi Arabia: a retrospective study of 26 cases and review of the literature. BJU Int. 2001;88(1):72-6. doi: 10.1046/j.1464-410x.2001.02243.x.

16. Khalil KH, O'Bichere A, Sellu D. Randomized clinical trial of sutured versus stapled closed haemorrhoidectomy. Br J Surg. 2000;87(10):1352-5. doi: 10.1046/j.1365-2168.2000.01624.x.

17. Ho YH, Cheong WK, Tsang C, Ho J, Eu KW, Tang CL, Seow-Choen F. Stapled hemorrhoidectomy--cost and effectiveness. Randomized, controlled trial including incontinence scoring, anorectal manometry, and endoanal ultrasound assessments at up to three months. Dis Colon Rectum. 2000;43(12):1666-75. doi: 10.1007/BF02236847.

18. Mehigan BJ, Monson JR, Hartley JE. Stapling procedure for haemorrhoids versus Milligan-Morgan haemorrhoidectomy: randomised controlled trial. Lancet. 2000;355(9206):782-5. doi: 10.1016/S01406736(99)08362-2.

19. Rowsell M, Bello M, Hemingway DM. Circumferential mucosectomy (stapled 
Annals of International Medical and Dental Research

E-ISSN: 2395-2822 | P-ISSN: 2395-2814

Vol-8, Issue-1 | January-February 2022

DOI: 10.53339/aimdr.2022.8.1.31

Page no- 235-242 | Section- Research Article (Surgery)

haemorrhoidectomy) versus conventional haemorrhoidectomy: randomised controlled trial. Lancet. 2000;355(9206):779-81. doi: 10.1016/s01406736(99)06122-x.

20. O'Connor JJ. Staplers and hemorrhoids. Dis Colon Rectum. 2000;43(1):118-9. doi: 10.1007/BF02237261.

21.Scales BS, Dickson RP, LiPuma JJ, Huffnagle GB. Microbiology, genomics, and clinical significance of the Pseudomonas fluorescens species complex, an unappreciated colonizer of humans. Clin Microbiol Rev. 2014;27(4):927-948. doi:10.1128/CMR.00044-14

Source of Support: Nil, Conflict of Interest: None declared 